\title{
WILLIAM FAULKNER Y SU NARRADOR TEMPRANO: LA VOZ DE QUENTIN EN ESE SOL DEL ATARDECER
}

\author{
William Faulkner and his early narrator: Quentin's voice in That Evening Sun
}

\author{
Luciana Colombo* \\ Universidad de Buenos Aires \\ colomboluciana@outlook.com
}

Palabras clave

narrador;

literatura norteamericana;

literatura sureña;

Faulkner

\section{Keywords}

narrator;

American Literature;

Southern Literature;

Faulkner

\begin{abstract}
Resumen
Este artículo analiza las principales características del narrador en la literatura de William Faulkner a partir de la mirada de uno de sus personajes más recurrentes, Quentin Compson, en Ese sol del atardecer. Dicho texto formó parte de Estos trece, un libro compuesto por los cuentos más exitosos del autor, escritos durante un momento crucial de su carrera, previo a la publicación de sus novelas más conocidas (Santuario, El sonido y la furia y Mientras agonizo). Se trata de un momento bisagra en la búsqueda de Faulkner por un estilo propio que refleja la verdadera naturaleza y la voz poética del sur. La proximidad con la muerte, el racismo estructural y los conflictos identitarios del sur postbellum están tematizados en el estilo y las imágenes con que Quentin narra esta historia. Involucrado emocionalmente en los hechos pero con suficiente distancia crítica como para narrarlos, el joven Quentin es un ejemplo de la complejidad narrativa diseñada por Faulkner.
\end{abstract}

\begin{abstract}
This article looks into the main components of one of the most renowned Faulknerian narrators, Quentin Compson, in That Evening Sun. It was part of These Thirteen, a book composed of Faulkner's successful stories written during a turning point of his life: prior to the publication of his best-known novels (Sanctuary, The sound and Fury and As I lay Dying). This short story represents a crucial moment in Faulkner's career, a period of seeking for an organic style that could comprehend the true nature and the poetic voice of the South. The proximity to death, structural racism and the postbellum conflicts on identity are present in the images that Quentin narrates in this short story. By being both emotionally involved in the course of events and maintaining a critically distant point of view, Quentin illustrates the complexity of narrative structure and elements implemented by Faulkner.
\end{abstract}




\section{William Faulkner y su narrador temprano: la voz de Quentin en Ese sol del atardecer}

\section{I.}

En este artículo se desarrollan algunas de las características más notorias del narrador faulkneriano tomando como paradigma la figura de Quentin en el relato Ese sol del atardecer, integrado en la compilación Estos trece. El cuento representa un momento de intensa búsqueda de un estilo propio, que años después alcanzaría la maduración con la publicación de sus primeras novelas. Si bien la fecha de publicación del libro es 1930, lo que lo colocaría en medio de una serie de publicaciones, las primeras apariciones del texto datan ya de 1929, y su elaboración se estima previa a la de sus dos grandes primeras novelas, The Sound and Fury y As I Lay Dying. Como en muchos de los cuentos de Estos Trece, en Ese sol del atardecer se trata la historia de un personaje, en este caso Nancy, al que Faulkner coloca en el centro de la escena indagando sobre sus tragedias, miedos y sentimientos más íntimos a través de la voz de un narrador testigo de los hechos. La frecuencia con la que Faulkner utiliza el punto de vista del narrador participante para contar la historia de diferentes personajes sureños resuena especialmente frente al siguiente pasaje autobiográfico:

Así que conseguí alguna gente, algunos los inventé, otros los creé a partir de cuentos que aprendía de cocineras negras y chicos de las cuadras de todas las edades entre Joby el de un brazo, de dieciocho, que me enseñó a escribir mi nombre en tinta roja en el guardapolvo de lino que llevaba por alguna razón que ambos habíamos olvidado, a la vieja Louvinia que recordaba cuándo "caían" las estrellas y que llamaba a mi abuelo y a mi padre por sus nombres de pila hasta que se murió. (Faulkner, 2012, p. 103)

Así, las historias de las que él mismo era observador se transforman en material ficcional. El Faulkner de finales de los años veinte ya había entendido, gracias a la influencia de autores como Mark Twain y Sherwood Anderson, que la fuente de originalidad de su escritura debía encontrarse en lo que le era más propio: los poetas iletrados, la música, la belleza de la tristeza que observaba en el sur (Faulkner, 2012, p. 84). De este modo, al estudiar la búsqueda faulkneriana de material narrativo en los habitantes de su sur natal, hay quienes identifican estas primeras historias como ejemplos de un realismo enraizado en el territorio y una definición sociohistórica de la identidad y relaciones sureñas (Smith, 2018; Knighton, 2019; Hartnell, 2010); o bien, como una obra con construcciones únicamente apreciables dentro de los límites del texto, que buscan la respuesta a la tragedia del hombre sureño sin pretender emular la realidad (Rollynson, 2020; Ferris, 2012; Duvall, 2011; Krause, 1985). Sin embargo, conviene estar atentos a la hora de disociar estas dos perspectivas en la obra de Faulkner y tener en cuenta las funciones de un narrador testigo pero inmensa y psicológicamente afectado por los hechos para poder comprender la verdadera naturaleza de historias como Ese sol del atardecer. 
El periodo de producción en el que se ubica esta narración es popularmente definido como un estadio intermedio entre una poesía sin éxito y el boom de las novelas (Rollynson, 2020; Jones, 2019; Brooks, 1978). Una etapa de creación de personajes, de historias que habrán de culminar en sus grandes novelas e historias residuales que Faulkner intentará publicar a toda costa por poco dinero, muchas de las cuales terminarán siendo compiladas en Estos trece. Si bien no se puede ignorar el objetivo claro en la mente del joven Faulkner de posicionarse como un escritor canónico de novelas, ${ }^{1}$ es asimismo necesario reconocer la capacidad de las historias de Estos trece como espacio donde Faulkner establece las bases de su personalidad literaria y de sus narradores. ${ }^{2}$

Como se sabe, el narrador constituye una construcción especialmente compleja en Faulkner, que posee rasgos específicos de la comunidad narrativa a la que pertenece. La voz de Quentin, por ejemplo, hace uso de una distancia crítica garantizada por el paso del tiempo, la desterritorialización y el acto mismo de narrar (Smith, 2018, p. 123), factores que, contradictoriamente, al mismo tiempo distorsionan y manipulan los objetos narrados y avanzan sobre ellos, modificándolos de acuerdo con sus propios objetivos narrativos. El narrador participante, de esta forma, enraíza su relato en la más profunda subjetividad y desarrolla el relato a partir de las emociones que los recuerdos y el paso del tiempo producen, avanzando sobre los hechos y haciendo peligrar, en consecuencia, la verosimilitud y la objetividad de la narración.

Como narrador, Quentin está cargado de lo que Flannery O'Connor (1988, p. 847) identifica como la exposición al conocimiento de las limitaciones humanas que el sur atraviesa luego de la Guerra de Secesión. Así, es capaz de narrar la decadencia de objetos que conforman su realidad, aun cuando sigue estrechamente unido a ella. La narración de Quentin alberga un pasado que se repite a sí mismo, siempre evanescente pero nunca ausente. En ella, aparecen personajes como Nancy dotados de un valor emocional intrínseco al narrador, y que le permiten a Faulkner lograr momentos líricos, de alto valor literario, aun en la lengua de sus personajes iletrados, a través de un narrador hábil como Quentin y sus memorias que vacilan entre el realismo y la elaboración poética.

1. El final de los años 20 se trata de un periodo de producción intenso en la vida del joven Faulkner: trabaja en la oficina postal de la Universidad de Mississippi y se dedica por las noches a escribir sobre Yoknapatawpha, el locus imaginario donde suceden todas sus historias. Mientras escribe sus novelas, publica diversos cuentos en revistas locales. Sus objetivos son muy claros: publicar y conseguir patronazgo. Para ello, se vincula con personajes editoriales como Horace Liveright (Watson, 2007), H. L. Mencken (Krause, 1985) y compañías como Four Seas Publishing Company (Jones, 2019). Rollynson (2020), Jones (2019) y Watson (2007) describen a Faulkner como un gran negociador a la hora de tratar con editores y revistas pese a su situación financiera inestable y, también, como un hombre preocupado por crear interés por su literatura y un estilo que cuenta "verdades" sobre el sur que pocos lectores de revistas como American Mercury conocen. Además, durante este periodo sentará las bases de una amistad con Sheerwod Anderson (Faulkner, 2012) en búsqueda de apoyo y consejo literario.

2. Asimismo, la práctica compositiva de Faulkner: la expansión de cuentos en novelas, el recorte de novelas en cuentos, posiciona a los cuentos como textos en diálogo con las novelas y a la vez los define como importantes elementos dentro de la serie literaria faulkneriana. 


\section{II.}

Ese sol del atardecer cuenta la historia de Nancy una señora negra del personal doméstico de la familia Compson. Acechada por su marido Jesus, que ha abandonado la casa al enterarse de un embarazo producto del ejercicio de la prostitución, busca la protección de la familia. Tras una secuencia de escenas narradas a partir de las fragmentarias memorias de Quentin, la búsqueda de garantía blanca de Nancy fracasa y la familia la abandona en la oscuridad de la noche. El entonces pequeño Quentin realiza un relato inconcluso donde los intentos de su memoria por aprehender la historia y el sentimiento de Nancy en aquel último contacto que tuvieron se transforman en una incógnita sostenida a lo largo del relato (Bollinger, 2012, p. 61). La presencia de Nancy se convierte en un conflicto para las identidades blancas con las cuales se relaciona, profundizando la búsqueda del sentido del narrador y los personajes. La misma narración escapa de asumir cualquier responsabilidad sobre lo narrado, evita toda aseveración sobre la historia y el destino de la mujer: "we could see Nancy's house and the open door, but we couldn't see Nancy now, sitting before the fire with the door open, because she was tired" (Faulkner, 1995, p. 309). Con este fragmento, una de las últimas intervenciones del narrador, el Quentin adulto deja al lector tan solo con el punto de vista del niño, que no termina de comprender la situación, como única herramienta para conocer la verdad.

La voz del cuentista sureño, ávido en el manejo de pausas, en la sonoridad de las palabras, profuso en historias, y en la manipulación del suspenso, le permite a Faulkner tomar contingencias de la narración oral (la alta emocionalidad del relato, los efectos del paso del tiempo en la memoria, la elaboración creativa) como puntapié para despegarse de las responsabilidades de verosimilitud y conclusividad del relato. Así, Quentin se permite no recordar en pos de ampliar el efecto emocional de la figura de Nancy. Es una muestra, por lo tanto, de que el narrador de Faulkner está implicado en la realidad que describe; se encuentra más allá de la simple narración, en relación directa (o indirecta, pero poco importa para el sur de Faulkner, para el narrador él siempre se encuentra implicado) con los hechos. La imagen de Nancy se vuelve en la consciencia del narrador un acertijo en relación con la muerte y, como contacto fundacional entre el mundo infantil y el racismo, afecta al propio narrador.

En este sentido, la posición de Quentin como sujeto de enunciación se ve atravesada por las relaciones entre los habitantes de Yoknapatawpha. En particular, en este como otros de los cuentos de Estos Trece se ponen en evidencia las relaciones entre blancos y negros movidas por el instinto de supervivencia (Knighton, 2019; Duvall, 2011; Hartnell, 2010). Estas relaciones son vividas en la literatura de Faulkner como una marca de la desesperación, la tragedia y la crisis del sujeto. En este caso, para una esclava como Nancy, la búsqueda de protección blanca es un debate entre la vida y la muerte. Asimismo, para Quentin, Nancy significa en su narración un punto desestabilizante, una fractura en el propio ámbito familiar producto de las relaciones raciales. Las palabras de Quentin no son capaces de afirmar, porque no lo sabe o porque no se atreve, si Nancy fue realmente abandonada a su suerte por la mano blanca en la que buscaba ayuda. No se afirma tampoco que haya muerto, ni que haya vivido. La historia de Nancy queda suspendida como un conflicto de la conformación identidad blanca en la infancia. 
III.

La idea de happening oral (Ashvo Muñoz, 2011, p. 221) permite pensar el cuento de Quentin a través de la atmósfera lingüística que construye, como "un desborde de voces y sonidos" en el que ambos discursos, el de Nancy y el de los chicos, se ponen en contacto mediados por la narración de Quentin. En este sentido, la voz de Nancy hace su primera aparición irrumpiendo en la voz del narrador. A partir de allí, Nancy se vuelve un personaje disruptivo tanto para el relato como para los personajes que interactúan con ella, para los chicos en primera instancia, ya que no son todavía sujetos blancos "completos", pero luego también para los adultos.

"When you going to pay me, White man? When you going to pay me, white man? It's been three times now since you paid me a cent". Mr Stovall knocked her down, but she on saying, "When you going to pay me, white man? lt's been three times now since" until Mr Stovall kicked her the mouth with his heel and the marshal caught Mr. Stovall back, and Nancy lying in the street, laughing. (Faulkner, 1995, p. 281)

Para los adultos blancos de la narración, la presencia de Nancy es, como mujer negra e insolente, evidentemente un malestar. Frente a esto la erupción de la violencia es inevitable y siempre parece que pudiera escalar un poco más.

Observar la estructura del primer manuscrito, publicado en Mississippi Quarterly (Moore Morrison, 1983), permite dar cuenta de muchas de las estrategias narrativas que construyen la atmósfera oral y la irrupción de la palabra de Nancy en la narración de Quentin. En Done No Weeping When [she] You Wanted to Laugh, Faulkner comienza desde el título experimentando con la lengua de los personajes. Hacia la versión final, las modificaciones se dan, principalmente, en el uso de elipsis que oscurecen las palabras en el entendimiento de los chicos y que amplifican las posibilidades del doble sentido frente a Nancy y Jesus.

"I can cut the one down it did come off of", Jesus said. "Yes you can", Nancy said. "I can cut off the one it's growing on", Jesus said. "I can do that". (Faulkner, 1983, p. 5)

"I can cut down the vine it did come off of", Jesus said: "What makes you want to talk like that before these chillen?”, Nancy said. (Faulkner, 1995, p. 292)

Aquí Faulkner trabaja con dos materiales distintos: oralidad y escritura. Nancy y Jesus hablan de forma oral, mientras que la cita de los chicos, que sustrae el sentido contextual de las palabras de Nancy, se produce en un lenguaje más lineal, escrito, más normativo y, por lo tanto, aleccionador. Sin embargo, la pregunta sin respuesta hace que el movimiento aleccionador, involuntario en los chicos, sea estéril (Laurel Bollinger, 2012; Krause, 1985). Muy por el contrario, funciona a favor de Nancy, ya que le permite volver a torcer los significados a su favor y utilizar este hueco para "hacerse" de la 
protección blanca. Los sonidos de Nancy, su voz, sus tonos, significan distinto y deben ser interpretados:

"Was it Jesus?", Caddy said, "Did he try to come into the kitchen?”. "Jesus", Nancy said. Like this: Jeeeeeesus, until the, sound. Went out like a match or a candle does. "It's the other Jesus shemeans", I said. (Faulkner, 1995, p. 296-297)

Las palabras de Nancy se deslizan entre el significado y el significante, la necesidad de interpretarla de a una frase a la vez, produce en los chicos preguntas cuya respuesta no encuentran más que entre ellos mismos y provisoriamente. Así, el intento de los chicos por leer la negritud de Nancy, se transforma en una pregunta por la propia negritud: ${ }^{3}$

"I aint a nigger", Jason said. "Are -you a nigger, Nancy?" "I hellborn, child", Nancy said. "I wont be nothing soon. (...) I aint a nigger", Jason said. “Am I, Dilsey?” "I reckon no”, Dilsey said. She looked at Nancy. (Faulkner, 1995, p. 298)

El conflicto frente a la pérdida de significado es lo que incita la búsqueda de control sobre Nancy. La multiplicidad de significantes -vacíos para los chicos- desemboca en intentos de búsqueda de sentido que, como reflejo de la lengua, se encuentran en la repetición, la cita y la apropiación de olores y sonidos que rodean a la protagonista.

Incluso la estabilidad de la propia voz de Quentin, como narrador, sucumbe frente a las erupciones del vernáculo. Al mismo tiempo, esa presencia del vernáculo profundiza la actividad de Quentin como narrador, que vuelve el habla de Nancy un elemento central de su narración y de la estructura del relato. Podemos imaginarlo, al narrar, imitando su voz. En este sentido, el trabajo de Faulkner sobre el primer manuscrito no solo ordena cronológicamente las escenas, suavizando la fragmentación y asimilando el relato con una narración oral, sino que además ubica más activamente a Quentin narrador dentro de la estructura del cuento, profundizando los efectos que el episodio tuvo en su identidad y que se conservan en su vida adulta. El relato se vuelca sobre los interrogantes que se desprenden de la figura de Nancy en los chicos y en el narrador, sus intentos por atraparla y luego abandonarla, y los efectos de su resistencia.

IV.

Mientras muchos de los elementos aludidos en el apartado anterior varían de la estructura original que Faulkner desarrolla en Done No Weeping When [she] You Wanted to Laugh, la canción de Nancy permanece como un objeto central en ambos relatos y, en especial, en el recuerdo de Quentin.

3. La negritud como una barrera no del todo discernible es un motivo frecuente en Faulkner, como han trabajado Oklopcic (2014) y Kim (2018). El passing es una fuente de conflicto y es también una fuente creativa para Faulkner que aparece en muchas de sus obras como jAbsalón, Absalón! y de una manera más productiva en Luz de Agosto. 
Faulkner ha pensado en la canción, y en ciertas metáforas vinculadas con Nancy, como la del fósforo que se consume o el sol del atardecer, desde el principio. En su análisis sobre las estructuras del relato, Laurel Bollinger (2012, p. 55) no logra justificar la presencia de la canción de Nancy como una instancia significativa del cuento. La canción tiene, en la lectura que aquí se realiza, una función primordial en la tarea del narrador por captar sus últimos momentos con Nancy.

Lo que muchos han identificado como el blues de Faulkner (Gartner, 1996; Peek, 2004; Gussow, 2002; Ferris, 2012) aparece más estrechamente vinculado con un sentido conciliador y religioso, de hecho, se vuelve mucho más productivo vincular la canción de Nancy con la tradición de las sorrow songs.

One night we waked up, hearing the sound. It was not singing and it was not crying, coming up the dark stairs. (...) The floor was cold. Our toes, curled away, from it while we listened to the sound. It was like singing and it wasn't like singing, like the sounds that Negroes make. (Faulkner 1995, p. 296)

Este tipo de momentos de tensión silenciosa mediados por la canción de Nancy aparecen dos veces en el relato siendo los más efectivos en términos dramáticos. No solo dan profundidad a la trama, sino que son verdaderos momentos de trascendencia para la narración de Quentin. El lamento que "hacen los negros" evoca un sentimiento religioso que da sentido a la experiencia.

Como explica Yusef Komunyakaa (2007), "The sorrow songs tell us that the African American church has always been a mecca for metaphor and double entendres. This music gives elastic voice to the desire for emancipation either in this world or the next" (p. 284). Para la propia Nancy se trata, evidentemente, de una canción que permite dar trascendencia a su miedo y aceptar la amenaza de muerte, a su parecer inminente. Bajo esta interpretación, la canción de Nancy, que termina por expulsar a los Compson sobre el final del cuento, la coloca en una posición distinta. Sobre el final del cuento, Nancy decide quedarse en soledad, acompañada solo por su canción.

En otro de sus primeros relatos, Red Leaves, Faulkner evoca nuevamente la historia de la búsqueda de escape como una decisión entre vida o muerte. Intentar salvarse se transforma, en la mente del esclavo retratado, en una reproducción de la historia del Middle Passage. Sin embargo, aunque "the slave wants to live, he understands he is also part of a mythos that requires his death" (p. 379). Este mito que marca el final no es otro que la picadura de la serpiente y la evocación a la cultura de los rituales vudú. Para el esclavo se trata tanto de salvarse como de interpretar los signos de un mundo que habla y transmite mensajes. ${ }^{4}$ La aceptación de la picadura de la serpiente en Red Leaves

\footnotetext{
4. Interesa para los fines del trabajo, específicamente la descripción de la lengua oral -tanto en comunidades orales primarias como secundarias- como "cerca del mundo humano vital" de Ong (2006). A partir de esto es posible pensar la lengua oral como una lengua donde los sonidos pautan los hechos del entorno. Por otro lado, las líneas que Gates abrió (1988) en El mono que significa, con el concepto de signifying, como manipulación elocuente de los significados sociales, ponen la atención en el significante, en tanto la entonación y el sonido de las palabras permite maleabilidad en su significado.
} 
así como el hueso sobre la mesa en Ese sol del atardecer son signos a través de los cuales se encauza la experiencia. Intentar sobrevivir, tanto como escuchar e interpretar los significados de la realidad y, en última instancia, aceptar la muerte, es parte de una manera de estar en el mundo y que Faulkner representa en constante conflicto con el mundo sureño blanco.

Sin embargo, en vez de un intento por representar concretamente los valores de la comunidad afroamericana, la presencia de la canción en la narración de Quentin es una muestra de angustia frente a la imposibilidad de aprehender los significados de la afroamericanidad: la canción de Nancy, la muerte circundante, la culpa y la responsabilidad blanca en las relaciones interraciales, se plantean como fantasmas para el narrador. Para Quentin, Nancy es una huella, ${ }^{5}$ sin embargo, no deja de carecer de fundamento afirmar que Nancy se vuelve solo un objeto sobre el cual afirmar identidad (Williams, 2015; Brown, 1976). Más bien se trata de un conflicto, de un momento con el que carga el joven Quentin. Más allá de la culpa del matrimonio Compson en el abandono de Nancy, hecho circunscripto al mundo de los adultos del relato e incomprensible para los niños, el miedo y la reconciliación de Nancy con la muerte producen en el joven Quentin un interrogante sobre el funcionamiento del mundo. Años después, cuando narra la historia, la culpa aparece: el personaje no intenta resolver qué sucedió finalmente con Nancy, tan solo se concentra en la marca que esa presencia transcendental tuvo en su infancia. En la narración se superponen ambas consciencias, la del niño y el adulto, profundizando la psicología del narrador como participante en los eventos y amplificando los efectos de las relaciones raciales, mostrándolas a lo largo del tiempo, a la luz del siglo veinte.

V.

Quentin se presenta como un intermediario que recupera la lengua, las voces, la música y los mitos de la cuenca del Mississippi, a la vez, el influjo de estos elementos produce en su consciencia momentos líricos. Para Faulkner, cada narrador representa una oportunidad de mostrar que todos los habitantes de Yoknapatawpha son poetas fecundos en el manejo del vivace y en la construcción de su propia figura como participante en los hechos. Muchas de las características del estilo Faulkneriano: la oración sin fin, las imágenes sensoriales, el punto de vista, se apoyan en las cualidades de un narrador hábil para esconderse o mostrarse, escudarse en la comunidad o expresar su propia visión, en búsqueda de un efecto o una pregunta en el oyente. En este sentido, los objetivos del narrador confluyen con los del escritor.

Como narrador, Quentin se deja influir por los objetos que narra y en esos momentos, los relativos a la canción de Nancy, la narración trasciende al nivel del marco y afecta emocionalmente la

5. Sobre este punto se vuelve interesante la lectura que Glissant realiza sobre Faulkner en su libro Faulkner, Mississippi (1966), donde recupera su estética como un punto de articulación de lo diverso, de la expresión de lo opaco del proceso de significación: la función del narrador, la acumulación, la repetición y la plasmación lingüística de la oralidad serían formas de narración de lo múltiple. La narración de Quentin sobre Nancy, la idea de happening oral (Muñoz, 2011), representa un desborde y una no traductibilidad de la realidad en la prosa. Nancy no es traducible en el texto, permanece críptica, oral e inaccesible en la conciencia del narrador. 
figura del narrador. Particularmente, estas escenas se tratan de momentos de empatía del narrador con lo narrado (Brooks, 1978). Del manuscrito a la versión final, Faulkner se esfuerza por eliminar el sesgo moralista de Quentin sobre la figura de Nancy, por lo que prepondera la repetición de la música y la profundidad su mirada por sobre las escenas de violencia. Sin embargo, la violencia es un elemento que sobrevuela la trama y la muestra de una relación problemática, intrincada y dolorosa -en la memoria de Quentin- entre blancos y negros. Nancy es una cocainómana sin mucho valor y, a la vez, una incógnita poética en la narración de Quentin, ambas al mismo tiempo. La huella de esta contradicción trabaja en la poética de Faulkner a través de la figura del narrador en tercera participante que recupera los motivos comunitarios no sin problematizarlos y cargarlos de violencia en la búsqueda -siempre incompleta- de su comprensión.

En el intento de hacer de su entorno un objeto de la alta literatura, Faulkner toma motivos afroamericanos como las sorrow songs para colocarlos en momentos más sublimes de su poética. El narrador se vuelve, entonces, una figura que se pregunta por la presencia de la muerte en la realidad que lo rodea, y elabora una respuesta emocional, íntima y nostálgica al narrar un episodio de su infancia vinculado con una canción religiosa. La imagen de Quentin que prefigura en este cuento habrá de condensarse años más tarde en un conocido pasaje de Absalom, Absalom!:

Then hearing would reconcile and he would seem to listen to two separate Quentins now-the Quentin Compson preparing for Harvard in the South, the deep South dead since 1865 and peopled with garrulous outraged baffled ghosts, listening, having to listen, to one of the ghosts which had refused to lie still even longer than most had, telling him about old ghost-times; and the Quentin Compson who was still too young to deserve yet to be a-ghost but nevertheless having to be one for all that, since he was born and bred in the deep South. (Faulkner, 1990, p. 6)

Ese sol del atardecer narra el periodo postbellum a partir del relato de Quentin como figura representativa de un periodo de crisis de estructuras del ser y el poder. En este sentido, el relato sobre Nancy -la voz de Nancy que irrumpe la narración como un rapto de emoción- no solo refleja la angustia de contacto, sino que se transforma en un catalizador de interrogantes y un desafío para la narración:

Nancy whispered something. It was oh or no, I don't know which. Like nobody had made it, like it came from nowhere and went, nowhere, until it was like Nancy was not there at all; that I had looked so hard at her eyes on the stairs that had got printed on my eyeballs, like the sun does when you have closed your eyes and there is no sun. (Faulkner, 1995, p. 296)

Estos momentos de dolorosa trascendencia suceden en la memoria de Quentin y en la de Faulkner como imágenes acústicas vívidas y difíciles de aprehender, como el sol del atardecer, como la cabeza de un fósforo ardiendo. Construcciones que se translucen a través de la relación dialéctica entre el racismo estructural del narrador, el pasado esclavista en constante reelaboración y 
descomposición, y una consciencia literaria que narra en vista del presente y de un público moderno, en un país unificado. Nancy es una existencia negra efímera, un recuerdo. Nancy reverbera constantemente en la repetición melódica, en imágenes discontinuadas contra toda posibilidad de narración monolítica que refleja una elaboración propia, un ensayo de respuesta a la decadencia del cuerpo y el territorio. Es, al mismo tiempo, un pecado con el que carga Quentin, un objeto sobre el que intenta infructuosamente afirmar su identidad blanca, una fuerza indomesticable exterior y una experiencia religiosa. En su no definición radica su fuerza como profunda incógnita sobre la identidad del narrador y la de su comunidad.

Algo que parece ser imposible: narrar una visión sobre la historia sureña y, a la vez, elaborar complejas metáforas, personajes inconclusos y mitos, se entrelazan armoniosamente en su literatura a través del narrador participante, cuyas características Faulkner define sobre el final de la década del veinte. Narrar lo que todavía no había sido narrado y pocos de los lectores de revistas conocían; recuperar lo más próximo a su historia personal y hacerlo arte elevado; crear un arte trascendente que se pregunte por la violencia de la historia: todos estos objetivos se cumplen en Ese sol del atardecer gracias a la coherencia, o la incoherencia, del narrador como partícipe de una comunidad, de sus mitos y de sus percepciones dispares y distorsionadas de la historia y la realidad. El narrador se vuelve un punto de intersección entre el realismo crítico y el arte modernista. Una muestra de un estilo capaz de captar al sur blanco en conflicto con sus culpas y sus pecados, y de dar a lo negro una presencia desafiante e indefinida para la identidad sureña. Una prosa capaz de representar la mirada directa al sol que queda impregnada en la retina aun cuando ya cerramos los ojos.

\section{Referencias bibliográficas}

Ashvo Muñoz, A. (primavera-otoño 2011). Voz de África. INTI, 73/74, 215-225.

Bollinger, L. (2012). Narrating Racial Identity and Transgression in Faulkner's “That Evening Sun”. College Literature 39, 2, 53-72.

Brown, M. C. (1976). Voice In "That Evening Sun”: A Study of Quentin Compson. The Mississippi Quarterly, 29 (3), 347-360.

Duvall, J. N. (2011). “A Strange Nigger”: Faulkner and the Minstrel Performance of Whiteness. En Watson, J. (ed.), Faulkner and Whiteness (pp. 92-106). Jackson, University Press of Mississippi.

Faulkner, W. (1990). Absalom, Absalom! En Faulkner, W., Novels 1936-1940. Nueva York, Library of America. (Original de 1936.)

Faulkner, W. (1995). ¡Absalón, Absalón! (F. B. Nelson, trad.). Barcelona, Atalaya. (Original de 1936.)

Faulkner, W. y Moore Morrison, G. (1983). Never Done No Weeping When You Wanted to Laugh. The Mississippi Quarterly, 36 (3), 461-474.

Faulkner, W. (2012). Ensayos y discursos (D. Sanchez Usanos, trad.). Madrid, Capitán Swing Libros. 
Faulkner, W. (1995). That Evening Sun. En Collected Stories (pp. 289-309). Nueva York, Vintage International. (Original de 1929.)

Faulkner, W. (1956). Estos trece (A. Bernárdez, trad.). Buenos Aires, Losada. (Original de 1929.)

Ferris, W. (2012). Southern Literature: A Blending of Oral, Visual \& Musical Voices. Daedalus, 141 (1), 139-153.

Gates, H. L. Jr. (1988). The Signifying Monkey. A Theory of African-American Literary Criticism. Oxford, Oxford University Press.

Hartnell, A. (2010). W. E. Du Bois, William Faulkner, and the dialectic of black and white: In Search of Exodus for a Postcolonial American South. Callaloo, 33 (2), 521-536.

Jones, G. (2019). Friction of Money: Poverty and Failure in early Faulkner. En Watson, J. y Thomas, J. G. (eds.), Faulkner and Money (pp. 90-109). Jackson, University Press of Mississippi.

Krause, D. (1985). Faulkner's blues. Studies in the Novel, 17 (1), 80-94.

Kim, K. (marzo de 2018). Passing for Black: Anti-Miscegenation Hysteria and Undercover Operation in William Faulkner's Light in August. CLA Journal, 61 (3), 188-206.

Komunyakaa, Y. (2007). Sorrow songs and flying away: religious influence on black poetry. CrossCurrents, 57 (2), 281-289.

Knighton, M. A. (2019). Racial debts, Individual slights, and Sleights of hand in Faulkner's Intruder in the Dust. En Watson, J. y Thomas, J. G. (eds.), Faulkner and Money (pp. 186-207). Jackson, University Press of Mississippi.

Ong, W. J. (2006). Oralidad y escritura, tecnologías de la palabra. Buenos Aires, FCE.

Oklopcic, B. (2014). Faulkner and the Native Keystone, Reading (Beyond) the American South. Berlin, Springer-Verlag.

Rollynson, C. (2020). The Life of William Faulkner: The Past Is Never Dead, 1897-1934. London, University of Virginia Press.

Smith, J. J. (2018). Resisting Identity. En The American Short Story Cycle (pp. 113-140). Edinburgh, Edinburgh University Press.

VV AA (2020). The Mythos and Ethos of America in the Work of William Faulkner: (1958). En History, Metaphors, Fables: A Hans Blumenberg Reader (pp. 476-498). London, Cornell University Press.

Watson, J. G. (2007). Faulkner to Liveright, September 18, 1928. The Mississippi Quarterly, 60 (3), 589-596.

Williams, T. (2015). How Faulkner Means Everything He Says: An Essay on James Baldwin's Politics of Intentionality. The New Centennial Review, 15 (3), 49-64. 
* Luciana Colombo es estudiante de la Licenciatura en Letras de la Facultad de Filosofía y Letras de la Universidad de Buenos Aires. Se desempeña actualmente como adscripta de la cátedra de Literatura Norteamericana, especializándose en literatura del sur de los Estados Unidos.

RECIBIDO: 25/02/2020

ACEPTADO: 02/08/2021 